\title{
Injuries among children in home and out-of-home
} care

\author{
J B Kotch, V M Dufort, P Stewart, J Fieberg, M McMurray, S O’Brien, E M Ngui, \\ M Brennan
}

\begin{abstract}
As the number of children receiving care in out-of-home settings increases in the United States, the risk of injury in such settings has become the subject of intense research.
\end{abstract}

Objectives-This study examined the relative safety of out-of-home care compared with care in a child's own home.

Methods-This community based prospective cohort study of 656 families in three adjacent counties in the Piedmont region of North Carolina characterizes the patterns and rates of injuries among children less than 5 years of age in three child care settings, home care (HC), center based care (CBC), and other outof-home care (OOHC). Information about minor and severe injuries was obtained from parents using monthly telephone interviews over a one year period. Statistical modeling designed to handle unbalanced data with correlated observations was used as the primary tool for analysis.

Results-Rate of minor injuries was highest in CBC, followed by HC, and then OOHC. However, these differences for OOHC may have been due to reporting biases and errors in rate estimates. There were no significant differences in severe injury rates among the three settings.

University of North Carolina at Chapel Hill: Department of Maternal and Child Health

JB Kotch

$S$ O'Brien

EM Ngui

M Brennan

Departments of Maternal and Child Health and

Epidemiology

VM Dufort

Department of

Biostatistics

P Stewart

J Fieberg

Frank Porter Graham Child

Development Center M McMurray

Correspondence to: Dr Jonathan B Kotch, Department of Materna and Child Health, CB\# 7400 Rosenau Hall, 7400 Rosenau Hall,
University of North Carolina, Chapel Hill, NC 27599-7400, USA.
Conclusions-The risk of serious injury among children under 5 in CBC is not different from that of children in $\mathrm{HC}$ or OOHC despite the fact that the risk of minor injury is higher.

(Injury Prevention 1997; 3: $267-271$ )

Keywords: child care; home care; out-of-home care; center based day care.

As the number of working mothers with young children continues to increase world wide, a significant proportion of infants (under 1 year of age), toddlers (ages 1-3), and preschoolers (ages 3-6) attend out-of-home care. In the United States, nearly $60 \%$ of mothers with children under 6 years of age work either full or part time. ${ }^{1}$ In addition, a recent national survey found that $40 \%$ of mothers with infants and $52 \%$ with toddlers are working either full or part time. ${ }^{2}$ Another study found that $60 \%$ of children 0 to 5 were attending out-of-home care regularly (V Cain, DA Dawson; paper presented at American Public Health Association meeting, Chicago, 1989). Furthermore, the proportion of infants in child care centers has quadrupled between 1976 and 1990, and the proportion of toddlers has almost doubled. ${ }^{2}$ The large cohort of children receiving out-ofhome care has led researchers to investigate the risk of infectious diseases and injury. ${ }^{34}$

Since out-of-home care for young children is a growing trend, and injury in this age group is a significant cause of morbidity and mortality, the safety in these settings has been of concern. Some investigators have looked at the epidemiology of injuries at child care centers. ${ }^{5-11}$ Others have studied hazards or the adherence to safety regulations in child care centers or family child care homes. ${ }^{12-14}$ Still others have sought to obtain a comparison of the rate of injuries in out-of-home care compared with care in a child's own home in an attempt to answer the question 'Is out-of-home care as safe as own-home care?'15-17 Two of these studies suggested that center based care was safer than home care, ${ }^{8-15}$ whereas two studies provide evidence that the rates of child care and home care injuries are not significantly different. ${ }^{11} 18$

The objective of this study was to compare injuries in three child care settings: (1) home care (HC), defined as care provided in a child's own home; (2) center based care (CBC), defined as child care services provided by an institution to six or more unrelated preschool children for four or more hours per day, including organized child care centers, nursery schools, Head Start centers, and preschools; and (3) other out-of-home care (OOHC), which included family child care homes (child care centers that provide services to fewer than six unrelated preschool children), babysitters, and any informal kind of child care provided in a place other than a child's own home.

\section{Study design and methods}

STUDY DESIGN AND POPULATION

This community based prospective study obtained injury information from a sample of families with children less than 5 years of age living in three adjacent counties in the Piedmont area of North Carolina. Households with telephones and at least one resident child under the age of 5 years were selected using random digit dialing. For the initial screening interview, at least four attempts were made at every sampled number to complete the interview. The calls were staggered over times of the day and days of the week to maximize the chances of making a contact. A total of 807 families was identified.

Of the original 807 eligible families, only 80 
(10\%) refused to participate. Thirty three (4\%) phones were no longer in service at the time of the first call, four families were not interviewed because of language or hearing difficulties, and $46(6 \%)$ could not be reached. A further 27 (3\%) were deemed ineligible at the time of the first interview contact because of either child disability or children no longer within the eligible age range.

Recruitment of 63 more families was attempted in December 1994. Five of the randomly selected numbers were business numbers. Of the remaining 58 families, 47 agreed to participate, increasing the potential sample to 664. Another eight families were lost, leaving 656 subjects who completed one or more of the monthly data collection calls.

\section{DATA COLLECTION}

An initial parent/guardian interview instrument was designed to establish baseline demographic and child care data. A second interview instrument was designed for use once a month for the next 12 months. Each month, a calendar was sent to respondents to record all injuries and to remind each of them of the coming phone call. The survey instruments were augmented by questions from the National Health Interview Survey and its 1988 Child Health Supplement (CHS). ${ }^{19}$ The injury questions used for the study conformed to the CHS. For each reported injury, information was collected on severity, type, cause, body part affected, care required, intentionality, day, time, and place of occurrence. Information on types of child care and hours of care was collected at the beginning of the study and updated whenever changes occurred. Information was also collected on age, gender, and race of the child, caretaker's education, housing density, and travel time to and from place of care.

\section{DATA VALIDATION}

The name of place of care was checked against state regulatory agency lists of registered child care facilities. Some discrepancies were noticed between reported place of injury and place of care. Whenever possible, these differences were resolved through follow up phone calls. If the discrepancy was not resolvable, the case was dropped from the analysis. As well, 57 injuries with 'questionable' dates that were not resolvable had to be dropped from the analysis.

Body part injured, type, and cause of injury were coded directly by the interviewers from a predetermined list. If injury information could not be coded, narrative information was recorded.

\section{CALCULATION OF EXPOSURE AND OUTCOME} Injury rates were calculated for the time period between 6:30 am and 5:29 pm, Monday through Friday. These rates were calculated by dividing the number of injuries in a particular setting by the number of hours of exposure. Hours of exposure for OOHC and CBC were obtained from the monthly tele- phone interviews. Hours spent at home were calculated as the time not engaged in either out-of-home child care or other activities of the home. The time spent in other activities. outside of the home was estimated by calling a random sample of study parents at the end of the study. Parents reported that, when thei $\overline{\bar{F}_{5}}$ children were not in child care, over $75 \%$ of their time was spent at home.

The total number of child care exposure hours between interviews was determined fron 8 the total number of weeks between completed interviews and the average hours of exposure per week. Injury rates were then calculated by dividing the number of injuries reported for $\vec{\varpi}$ given setting by the number of hours o. exposure in that setting since the previou品 interview.

For all analyses, gender, age, household density (people per room) and primary care-taker's education (usually mother: years of school completed) were examined as potentiat confounders.

Injuries were classified as either severe oळ minor. Severe injuries were defined as anto injury for which a health care provider was visited and/or the child's normal activity waso limited for four or more hours. Minor injuires included any injury that required only first aid without any direct (non-telephone) assistances from a health care provider, and the child's normal activity resumed in fewer than fout hours.

\section{STATISTICAL ANALYSIS}

Log linear statistical modeling, designed tôे handle unbalanced data with correlated observations, was used as the primary analytic tool.

In addressing the research question, the regression equation included care setting $₫$ severity, sex, child's age, caretaker's years of completed education, and housing density? (persons per room in the child's home). This model was used to obtain sex specific estimatesi of the mean rates of severe and minor injury for each of the three settings, with adjustment too the average levels of age, education, and housing density. Caretaker's education and housing density were chosen as indicators of socio
economic status.

\section{Results}

PROFILES OF CHILD CARE HOURS status at the beginning of the study, 35\% $(226)^{\frac{\omega}{+}}$ had only HC, while $65 \%$ (429) had some out $-\frac{T}{2}$ of-home care arrangement. Of these 429 월 children, $25 \%$ (108) spent fewer than 20 hours? a week in out-of-home care settings compared@ with $75 \%$ (321) who spent 20 or more hours aर week in such settings. The models used in this? study allowed for changes in child care status throughout the study period, and used time⿳亠丷厂 spent in the specified setting as the denomi? nator.

While only about one third of all children were cared for exclusively in their own homes, 
HC accounted for over $65 \%$ of the total daytime hours of exposure per week. After ajusting for time spent traveling and in activities other than child care, HC accounted for $59 \%$ of the total exposure time, followed by CBC with $29 \%$, and OOHC with $13 \%$.

\section{AGE AND SEX}

Three age groups were used in the analysis: $<1$ (101), $1-<3$ (278), and $\geqslant 3$ years (277). Males and females were nearly equally represented in the totals and within each care setting.

RACE

The racial distribution of the total sample (70\% white $/ 23 \%$ African American $/ 7 \%$ other) was approximately representative of the racial distribution of North Carolina. ${ }^{20}$ However, there were fewer white children in child care settings $(63 \%)$ than there were among children cared for exclusively at home $(77 \%)$.

\section{CAUSE OF INJURY}

Altogether 944 of the 971 reported injuries had complete information on cause and place of occurrence. The most common cause in all child care settings was falls (51\%). Being struck by a blunt or sharp object was the second leading cause (32\%), followed by human bites $(8 \%)$. The distribution of injury causes among care settings followed the same pattern; however, human bites were more prevalent in CBC ( 61 of 72 bites), and there were fewer injuries caused by sharp or piercing objects in CBC.

\section{TYPE OF INJURY}

Cuts and scrapes were the most frequent injury (65\%), followed by bruises (12\%), swelling/ bumps (12\%), burns/reddened skin (3\%), and superficial foreign bodies (2\%). Incidents that were classified as 'no injury' included swallowing coins and choking on food and resulted in no visible damage. The distribution of injury types across care settings followed the same patttern, although burns tended to occur more frequently in HC settings (26 of 33 injuries).

\section{BODY PART INJURED}

Of the 970 injuries where body part and place of injury were identified, $44 \%$ involved the head and neck, $24 \%$ the upper extremities, $28 \%$ the lower extremities, and $4 \%$ the torso. Head and neck injuries were relatively more common in $\mathrm{OOHC}$ and $\mathrm{CBC}$ than in $\mathrm{HC}$, whereas injuries to the lower extremities were more common in $\mathrm{HC}$ than in OOHC or CBC. Because of low numbers, the distribution of OOHC injuries should be interpreted with caution.

\section{CRUDE INJURY RATES}

A total of 971 injuries were reported as occurring in all child care settings over the study year, of which severe injuries comprised $6 \%$. Among the severe injuries, about $66 \%$ occurred at the children's own homes compared with $32 \%$ in CBC settings and none in OOHC. None of the reported injuries required hospitalization. Among the minor injuries, approximately $54 \%$ took place in the home, compared with $42 \%$ in $\mathrm{CBC}$ and $4 \%$ in OOHC settings. In all three settings, the crude injury rates among boys were higher than for girls.

A similar pattern of crude injury rates was observed for severe injuries in HC and CBC. Rates among boys in $\mathrm{HC}$ were 5.4 injuries per 100000 child hours compared with 3.2 injuries per 100000 child hours among girls. In CBC the corresponding rates for boys were 6.0 and 2.9 for girls.

\section{INIURY RATES FROM THE LOG LINEAR MODEL}

Minor injuries

For minor injuries, the adjusted rates were higher in CBC (64 injuries per 100000 hours) compared with HC (45 injuries per 100000 hours) and OOHC (14 injuries per 100000 hours) (table). These differences were statistically significant for all comparisons, even after adjusting for multiple comparisons $(p<0.05)$. This analysis was also performed separately for the three age groups. While total rates differed by age, the differences among child care settings remained essentially the same.

\section{Severe injuries}

The adjusted severe injury rate for $\mathrm{CBC}$ was 3.5 injuries per 100000 child hours compared with 3.3 in HC and 0.1 in OOHC settings. The adjusted injury rates for these settings according to age groups are shown in the table. There were no statistically significant differences in severe injury rates among the three child care settings, nor was there any difference in child care setting injury rates in their age groups.

\section{Discussion}

This is the first community based study to describe injury rates and patterns of injuries, based on monthly parents' reports, among preschool children in the United States in relation to exposure to out-of-home care. One clear advantage of using parents' reports is that minor as well as severe injuries were identified, reducing the effort needed to obtain statisti-

Adjusted ${ }^{*}$ injury rates per 100000 child hours by place of occurrence and age group; values are mean (SE)

\begin{tabular}{llll}
\hline $\begin{array}{l}\text { Age groups } \\
\text { (years) }\end{array}$ & $H C$ & $C B C$ & OOHC \\
\hline $\begin{array}{l}\text { Severe injuries } \\
\text { All ages }\end{array}$ & $3.32(0.39)$ & $3.46(0.54)$ & $0.10(1.51)$ \\
$\quad<1$ & $2.36(0.48)$ & $2.45(0.59)$ & $0.07(1.33)$ \\
$1-<3$ & $4.42(0.44)$ & $4.60(0.63)$ & $0.13(1.76)$ \\
$\geqslant 3$ & $3.43(0.40)$ & $3.59(0.52)$ & $0.10(1.51)$ \\
Minor injuries & $44.5(0.63)$ & $63.2(1.05)$ & $13.7(0.85)$ \\
All ages & $31.6(1.32)$ & $44.9(1.71)$ & $9.7(0.96)$ \\
$\quad<1$ & $59.5(0.70)$ & $83.9(1.36)$ & $18.2(1.00)$ \\
$1-<3$ & $46.0(0.67)$ & $65.6(0.89)$ & $14.1(0.91)$ \\
$\geqslant 3$ &
\end{tabular}

* Adjusted for sex, caretaker's education, and housing density. 
cally significant results. Assuming a difference on the order of 1.4 times the rate of injuries between any two child care settings (as was seen with the minor injuries between $\mathrm{HC}$ and CBC, for instance), one would have to analyze 200 severe injuries to get $95 \%$ probability of obtaining a significant result. At the rate of 1.5 severe injuries per 100000 child hours, that would mean following up more than 6600 children over the course of one year. This estimate does not take into account stratification by age or controlling for covariates in the models, which greatly increase the sample size required. Although minor injuries by themselves may not present significant health consequences, they may serve as sentinels for severe injuries.

Most of the work done previously on out-ofhome care injuries has only examined severe injuries, ignoring minor injuries. Overpeck and Kotch have shown that limiting countable injury to those that are medically attended may miss up to $40 \%$ of injuries that have important consequences, such as activity limitations. ${ }^{21}$ Furthermore, including minor injuries would provide more complete information about the epidemiology of child care injuries. Human bites, for example, are a type of injury whose true incidence may not be revealed if only severe injuries are studied. ${ }^{1822}$ Minor injuries can also serve as a marker of potentially hazardous situations.

Although more than one study has come to the conclusion that out-of-home care is as safe and possibly safer than $\mathrm{HC},{ }^{815}$ the validity of these studies is limited by selection biases and study design. In addition, the relative safety of child care centers versus family child care homes and informal child care arrangements has received little attention. Family child care homes are a distinctly different setting from larger, organized child care centers. Turner and coworkers compared child care centers and family child care homes in North Carolina. ${ }^{23}$ They observed that injury rates were twice as high in child care homes than in child care centers, although more severe injuries occurred at child care centers. However, these conclusions are based on only 66 injuries, of which 11 occurred in child care homes. Gunn and associates also reported a higher incidence of injuries for family child care homes as an incidental finding. ${ }^{16}$ This finding was not tested for statistical significance and comprised only 24 injuries.

While this study failed to find any statistically significant differences between severe injury rates among the different child care settings, this does not rule out the possibility that there were such differences. If the rate differences were close to 1.4 , as with the minor injuries, this study would not have had the power to reveal these differences. However, it is not likely that severe injuries would have been lower in child care centers than in children's own homes, as earlier research has suggested.

This study was the first to employ sophisticated statistical modeling to control for the non-independence of multiple injuries. Failure to do so could lead to an overestimation of the effect of care setting on injury rates. These models also allowed controlling for potentiat confounders, that is, to take account of

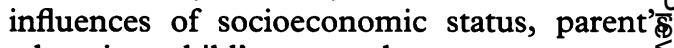
education, child's age, and sex.

Another strength of this study was that it was able to capitalize on the information obtainet by identifying minor injuries. In other words asking about minor injuries may have imsproved parents' recall of major injuries. Car was taken to account for time spent outside of the different care settings, so the number of exposure hours in own home care was nol inflated. Failure to account for time spent outside of the specific care settings would have led to an underestimation of the actual rate $\overline{\text { of }}$ home injuries.

One possible limitation of this study stemis from the way injuries were identified. Because parents were the sole source of this informa음 tion, it is conceivable that minor injuries occurring outside of the home would be under-reported. Validation of parental report\$ with center records was not carried out However, steps were taken to reduce the probability of recall biases. On two occasion $\overrightarrow{8}$ each month, parents were reminded of the study. Parents were sent calendars each montb on which they were asked to record all injuries? They were also contacted monthly for a brie telephone interview. While shorter interview intervals may have improved the capture of minor injuries, recall bias should not differen tially affect home versus out-of-home injur rates.

In the case of $\mathrm{CBC}$, the higher rates of reported minor injuries would lead us to conclude that under-reporting did not happeneHowever, the remarkably low injury rates for OOHC suggests that some injuries in this setting may have been overlooked. Given the higher level of organization in CBC, the fac年 that these centers are more closely regulated? and the imminent introduction of mandatory child care injury reporting systems in North Carolina, it is possible that CBC centers would already be more aware of, and responsive to, 3 tracking system, thus reporting even minor injuries to parents. In contrast, the OOHE settings, given that they are largely unaffecte by the reporting regulations, would be less' likely to record or recall injuries, or to reporty these injuries to the parents. A final possible reason for the low rates in OOHC may be due to the relatively low total exposure time increasing the unreliability of injury rat estimates and to less exposure to the large? pieces of playground equipment associated with institutional style child care.

In support of the argument that this studP reliably increased the capture of serious ine juries by using parental reports of all injuries the distribution of injury causes is similar t 8 that of studies using other methods of injure identification. In this study, falls were the leading cause of injury, which is consistent with other studies. ${ }^{917}$ Injuries caused by human bites were more common in CBC than in other child care settings, and these findings are 
similar to those of Kotch et al, who found human bites to be the second most common injury cause in child care centers. ${ }^{18}$

The distribution of injury types was also consistent with other studies. The leading injury type was scrapes/cuts, followed by swelling/bumps, bruises, and burns. Cuts and bruises accounted for over $40 \%$ of $\mathrm{HC}$ injuries and $25 \%$ of injuries in out-of-home care in the study of Gunn et al, ${ }^{16}$ and most burns occurred only in $\mathrm{HC}$, findings similar to ours.

However, when comparing rates of severe injuries, differences become apparent between this and other studies. Gunn and associates, for example, found the rates of injury in out-ofhome care to be 1.69 injuries per 100000 child hours. ${ }^{16} \mathrm{~A}$ study of medically attended injuries in child care settings found rates of 1.56 injuries per 100000 child hours. ${ }^{24}$ In this study, the risk of injury in CBC was 3.46 injuries per 100000 child hours for severe injuries. This twofold higher rate of injuries was certainly due, to a certain extent, to the more liberal definition of severe injuries. A study assessing injuries arriving at the emergency department would certainly miss any injury that had medical attention elsewhere, or which resulted in activity limitations but no medical visits.

While the sampling strategy employed in this study ensured a reasonable representation of eligible families, it is limited by the exclusion of families without telephones. Poorer families, who couldn't afford telephones, would also be less likely to have access to child care outside of the home. However, because child injury rates increase as income decreases, this bias would have led to relative underreporting of out-ofhome injuries. In any event, since neither caretaker's education nor housing density, both indicators of socioeconomic status, were significantly associated with injury rates in this study, it is unlikely that including families without telephones would have influenced the study's conclusions.

\section{Implications for prevention}

There is a need to pay continuing attention to the safety of young children, both in child care and HC. Burns are a special concern for children at home, while falls from heights needs to be a focus for child care providers, particularly in organized child care centers where there is more and bigger playground equipment. Training of child care providers should emphasize playground safety and knowledge of peak times of injury (afternoons and late mornings).

Our report, along with other recent work such as Kopjar and Wickizer's study, shows that complacency with respect to child care safety issues should be discouraged. ${ }^{17}$ Safety in child care is an ongoing concern. Health care providers should be trained to follow up and keep records of child care injuries, and reliable child care injury surveillance systems are needed. Training in injury prevention (in addition to first aid and cardiopulmonary resuscitation) should be required for all child care workers.
As changes come about in child care regulations, further research can focus on the effects of changes in regulations on the types and causes of injuries in different care settings. More detailed studies may also help in identifying previously unknown or unsuspected hazards. Finally, there is a need for evaluation of the impact of the regulation of safety hazards in child care and of other injury control interventions on the frequency and severity of injuries in preschool children.

Our thanks to Susan Alber, Betsy Crites, Laura Fish, Marcia Herman-Giddens, Jin-Whan Jung, Veronica Lawrence, Lauren Watterson, and Rick Williams.

This study was supported in part by grant \#MCJ-370363 from the Maternal and Child Health Research Program Maternal and Health Bureau, Health Resources and Services Administration, Public Health Service, United States Department of Health and Human Services.

1 Deitch SR, ed. Health in day care: a manual for health professionals. Elk Grove Village, IL: American Academy of Pediatrics, 1987.

2 Willer B, Hofferth SL, Kisher EE, et al. The demand and supply of child care in 1990: joint findings from the national child care survey, 1990 , and a profile of child care settings. Washington, DC: National Association for the Education of Young Children, 1990.

3 Haskins R, Kotch JB. Day care and illness: evidence, cost and public policy. Pediatrics 1986; 77 (suppl 6) 951-82.

4 Kotch JB, Bryant D. Effects of day care on the health and development of children. Curr Opin Pediatr 1990; 2: 883 94

5 Landman P, Landman G. Accidental injuries in children in day care centers. Am 7 Dis Child 1987; 141: 292-3.

6 Elardo R, Solomons HC, Snider BC. An analysis of accidents at a day care center. Am f Orthopsychiatry 1987; 57: $60-5$.

7 Chang A, Lugg MM, Nebedum A. Injuries among preschool children enrolled in daycare centers. Pediatrics 1989; 83: $272-7$

8 Sacks J, Smith DJ, Kaplan KM, Lambert DA, Sattin RW, Sikes RK. The epidemiology of injuries in Atlanta daySikes RK. The epidemiology of injuries
care centers. $¥ A M A 1989 ; 262: 1641-5$.

9 Briss PA, Sacks J, Addiss DG, Kresnow M, O'Neil J. A nationwide study of the risk of injury associated with day care center attendance. Pediatrics 1994; 93: 364-8.

10 Alkon A, Genevro JL, Kaiser PJ, Tschann JM, Chesney M Boyce $T$. Injuries in child-care centers: rates, severity, and etiology. Pediatrics 1994; 94: $1043-6$.

11 Sellstrom E, Bremberg S, Chang A. Injuries in Swedish daycare centers. Pediatrics 1994; 94: 1033-6.

12 O'Connor MA, Boyle WE, O'Conner GT, Letellier R. Selfreported safety practices in child care facilities. Am $\mathcal{f}$ Prev Med 1992; 8: 14-8.

13 Wasserman RC, Dameron DO, Brozicevic MM, Aronson RA. Injury hazards in home day care. $₹$ Pediatr 1989; 114: 591-3.

14 Browning KS, Runyan CW, Kotch JB. A statewide survey of hazards in child care centers. Injury Prevention 1996; 2: 202-7.

15 Rivara FP, DiGuiseppi C, Thompson RS, Calonge N. Risk of injury to children less than 5 years of age in day care versus home care settings. Pediatrics 1989; 84: $1011-6$.

16 Gunn WJ, Pinsky PF, Sacks JJ, Schonberger LB. Injuries and poisoning in out-of-home child care and home care. Am $\mathcal{f}$ Dis Child 1991; 145: 779-81.

17 Kopjar B, Wickizer T. How safe are day care centers? Day care versus home injuries among children in Norway. Pediatrics 1996; 97: 43-7.

18 Kotch JB, Loda F, Harms T, Clifford RM, McMurray MP. Parents' report of home and out-of-home injuries among children attending child care centers. Early Child Development and Care 1993; 96: 183-3.

19 US Department of Health and Human Services, National Center for Health Statistics. National health interview survey: child health supplement. US Department of Health and Human Services, National Center for Health Statistics [producer], 1987. Ann Arbor, MI. InterStatistics [producer], 1987 . Ann Arbor, MI: Interuniversity Consortium

20 US Bureau of the Census. Census of population and housing. Washington, DC: US Department of Commerce, 1990.

21 Overpeck MD, Kotch JB. The effect of US children's access to care on medical attention for injuries. Am $\mathcal{f}$ Public Health 1995; 85: $402-4$.

22 Garrard J, Leland N, Smith DK. Epidemiology of human bites to children in a day-care centre. $A m \mathcal{F}$ is Child 1988; 142: 643-50.

23 Turner WT, Snow CW, Poteat GM. Accidental injuries among children in daycare centers and family day care homes: brief report. Children's Health Care 1993; 22: 73-9.

24 Rivara FP, Sacks J. Preventing injuries and improving the environment: injuries in child day care: an overview. Pediatrics 1994; 94: $1031-3$. 